\title{
HEAT TRANSFER MODELLING OF TWO-PHASE FLOW IN ISOLATED CHANNEL
}

\author{
Daniel VlČé*, Vojtěch Caha, Martin ŠevečeK
}

\author{
KJR FJFI ČVUT, V Holešovičkách 2, Praha 8, Czech Republic \\ * corresponding author: daniel.vlcek1@gmail.com
}

\begin{abstract}
This paper deals with Post-CHF (critical heat flux) heat transfer with the focus on different regimes of film boiling. The new thermal-hydraulic code TUBE 2.0 is presented. This code uses the equation of energy conservation and predefined correlations to establish wall temperature, the departure of nucleate boiling ratio as well as other parameters of cooling in a simple geometry - an isolated channel. With experimental data of inverted annular film boiling from Stewart, the best-performing correlation for calculation of post-CHF heat transfer in the channel was determined. Finally, the new presented code TUBE 2.0 and subchannel code SUBCAL owned by Chemcomex a.s. are compared using results of various experiments conducted by Becker. Data from Stewart could not be used because of inability to predict the onset of boiling crisis with several correlations.
\end{abstract}

Keywords: Post-CHF, Heat transfer, Modelling and Simulation, Two-phase Flow, Correlations, Experimental data.

\section{INTRODUCTION}

Since 1978 when the "hot patch" technique was used by Groeneveld (1978) to arrest the quench front and establish stationary film boiling in a heated tube, an increasing amount of steady-state film boiling heat transfer data has been obtained in various laboratories all over the world. At first, the refrigerants were used as a medium. Later, the first experiments with water were performed by Fung [1] at atmospheric pressure or by Stewart at a wider range of parameters [2]. The simplest test-section used for these types of experiments is a single-tube geometry 3 .

Although a lot of experiments with hot patch were conducted, there is lack of film boiling heat transfer correlations in these specific conditions. During the conditions, in which the hot patch experiments are performed, the inverted annular film boiling (IAFB) mostly occurs and as it is shown further, it can not be considered as dispersed flow film boiling (DFFB).

This heat transfer regime generally occurs at low qualities and sub-cooled conditions at void fractions less than 0.5. Low quality here goes hand in hand with high heat flux. The main characteristics of IAFB are the low heat transfer coefficients due to vapor film covering the channel wall. The phase distribution during IAFB consists of a continuous liquid core at the center of the channel surrounded by a vapor blanket covering the heated surface as it is shown in the Fig. 1 where the IAFB regime is schematically presented in the right tube. The development of phases is clearly different in these regimes and the same applies for the approach to estimating heat transfer coefficient [4].

Heat transfer by radiation from the wall to the liquid is important when the wall temperatures are greater than $600{ }^{\circ} \mathrm{C}$, yet the most important change from DFFB regime is dealing with the heat transfer through vapor film. The vapor film is assumed to have a higher velocity than the liquid core, and the vapor velocity increases together with the vapor layer thickness. This is due to the low viscosity and low density of the vapor, which enables the vapor flow to experience a higher acceleration than the dense core flow 3 .

\section{COMPARISON OF CORRELATIONS}

In order to compare several correlations for postCHF heat transfer coefficient, new computational code TUBE 2.0 was created. Before introducing the code, the experimental data and available corelations will be described first.

\subsection{Stewart EXPERIMENTS}

For the purpose of the comparison, the Stewart's [2] film boiling experimental data with the focus on IAFB regime were chosen. The experiments were conducted on MR-1 FLARE LOOP in Chalk River laboratories. The test section was made of $207.1 \mathrm{~cm}$ long Inconel 600 tube with inner diameter $0.8928 \mathrm{~cm}$. Indirect method of $10.1 \mathrm{~cm}$ long hot patch was used here and the loop was capable of providing pressure in range $2.0-10.0 \mathrm{MPa}$ and mass flux in range 120 $2750 \mathrm{~kg} \cdot \mathrm{m}^{-2} \cdot \mathrm{s}^{-1}$.

Wall temperatures were measured with twenty thermocouples spread out over the whole test section, however, the inlet section was covered more densely. Experiments were divided into 51 runs with different inlet subcooling, mass flux, and pressure. Heat flux was slowly changed during each run in order to obtain minimum film boiling temperature data. So the heat flux was relatively low for estimation of $\mathrm{CHF}$ as it is stated further. 


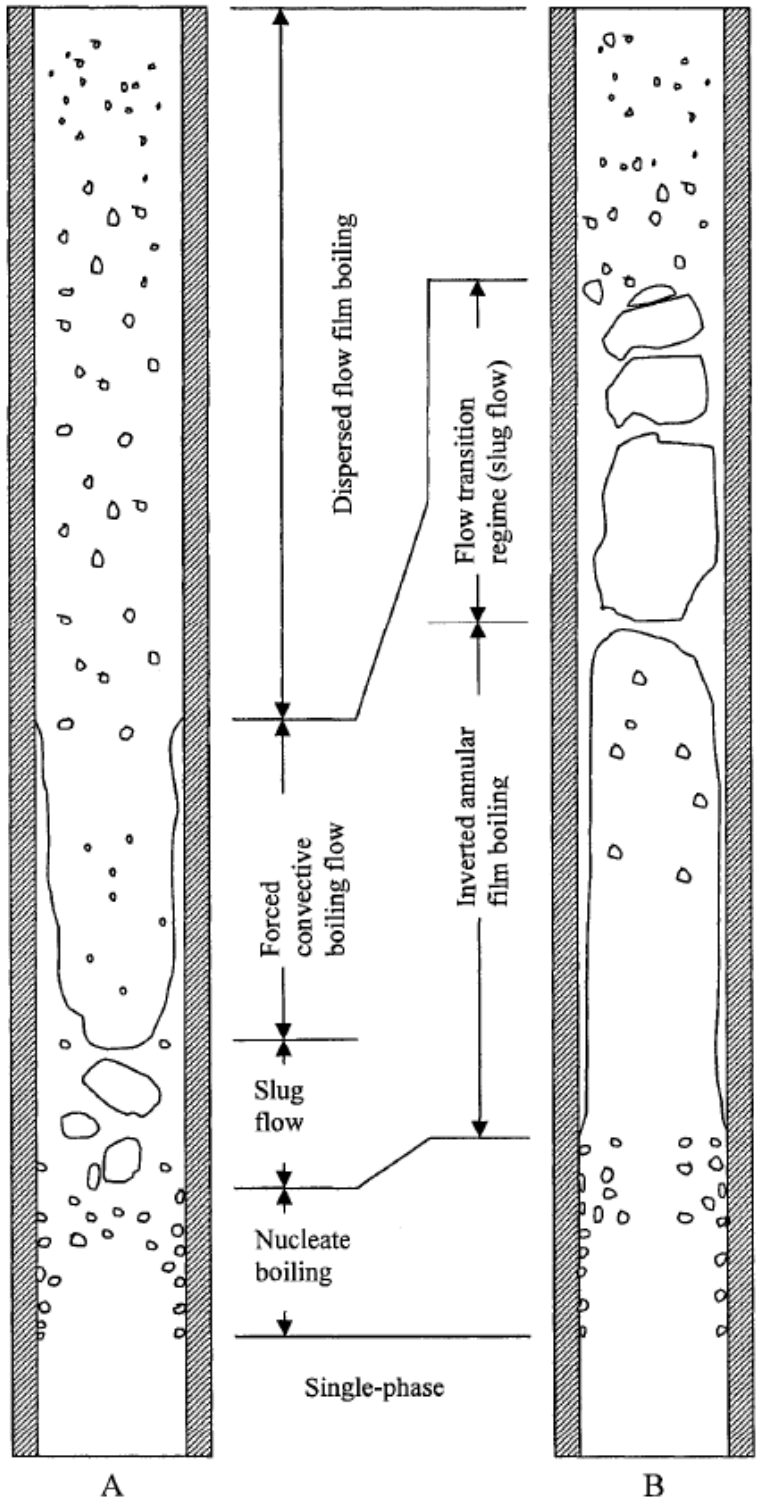

Figure 1. The difference between IAFB (right) and DFFB (left) regime inducted by different heat flux 4.

\subsection{TUBE $2.0 \mathrm{CODE}$}

The TUBE 2.0 [5] code further develops the code TUBE created at Department of Nuclear Reactors, CTU in Prague. TUBE 2.0 is based on the equation of energy conservation and predefined correlations to establish wall temperature, the departure of nucleate boiling ratio as well as other parameters of cooling in a simple geometry - an isolated channel. It allows calculating with two-phase flow using the homogeneous equivalent model with respect to thermal non-equilibrium.

This code exceeds the complex programmes with its easy manipulation and with a possibility to define own correlations whether it is for predicting of boiling crisis, for computation heat transfer coefficient in post-

\begin{tabular}{l|c} 
Correlation & Regime \\
\hline \hline Dougall-Rohsenow [6] & DFFB \\
Groeneveld-Delorme [7] & DFFB \\
Condie-Bengston [8] & DFFB \\
Groeneveld's tables [9] & DFFB/IAFB \\
Bromley [10] & IAFB \\
Berenson [11] & IAFB \\
Breen-Westwater [12] & IAFB \\
Mosaad-Johannsen [3] & IAFB
\end{tabular}

TABle 1. Compared post critical correlations in TUBE 2.0.

\begin{tabular}{l|c} 
Correlation & Range of p [MPa] \\
\hline \hline Biasi [14] & $0.27-14.0$ \\
Bowring [14] & $0.2-19.0$ \\
Zuber [14] & No limits \\
Smolin [14] & $3.0-10.0$ \\
PG-T [15] & $0.3-18.7$ \\
OKBM Bezrukov [15] & $9.7-18.0$ \\
CHF - lookup tables [16] & $0.1-20.0$
\end{tabular}

TABLE 2. Used correlations for predicting CHF.

CHF regime etc. It was written in Fortran language which was chosen for its short computation time.

Around 15 post-CHF heat transfer correlations were defined in TUBE 2.0, however, most of them are meant for DFFB regime. The chosen correlations for comparison are shown in Tab. 1. On the basis of previous work of Vlček [13] the best performing correlations of DFFB regime that could be used for low-quality data were chosen. Tables from Groeneveld cover a wide range of application. The equations from Berenson and Breen-Westwater are derived from Bromley's and finally, correlation from Mosaad and Johannsen was determined partly on basis of Stewart's data and should be one of the best correlations for IAFB regimes according to Mosaad [3].

The Stewart's experimental data are post critical so the computation code must predict the onset of boiling crisis before it starts to use post critical correlations. For that purpose, the correlations shown in the Tab. 2 were chosen. The selection of equations was broad enough to cover all potential inaccuracies caused by approaching lateral parts of ranges. In these parts is the precision of predicting significantly worse. However, even with this wide selection it was not possible to achieve post-critical regime. The onset had to be set manually into two-thirds of hot patch section according to Stewart's experimental measurements of temperature drops.

The problems with estimation of CHF were probably caused by very low qualities and also by lowering heat flux in order to obtain minimum film boiling data. However, these results were unexpected and show that there is a need for new predicting correlations of $\mathrm{CHF}$ for IAFB regime because these conditions may occur during the rewetting phase of LOCA. 


\begin{tabular}{l|c|c} 
Correlation & AVG [\%] & STD [\%] \\
\hline \hline Condie-Bengston & 0.31 & 0.21 \\
Groeneveld 5.7 [14] & 0.12 & 0.10 \\
Groeneveld 5.9 [14] & 0.13 & 0.11 \\
Groeneveld-Delorme & 0.11 & 0.05 \\
Groeneveld's tab. & 0.18 & 0.14
\end{tabular}

TABLE 3. The statistical summary of comparison of TUBE 2.0 and SUBCAL with the use of 12202 points from Becker's experimental database.

\subsection{VALidATION OF TUBE 2.0}

At the beginning of the validation process of the new computational code TUBE 2.0, the experimental data from Stewart could not be used, so the data from Becker [17] were selected instead. The experiments were conducted in Stockholm at the Royal Institute of Technology and the database provides more than 15,000 experimental data points of post-critical heat transfer in $7 \mathrm{~m}$ long tube with variation of three diameters from 1 to $2.47 \mathrm{~cm}$ with pressure range 3 $20.5 \mathrm{MPa}$, mass flux range $500-3000 \mathrm{~kg} \cdot \mathrm{m}^{-2} \cdot \mathrm{s}^{-1}$ and quality from -0.03 to 1.66 . The boiling regime was DFFB so there was no need for IAFB correlations.

\section{Results}

\subsection{VALIDATION}

In the first part of validation process - code-to-code comparison, complex code SUBCAL [15] owned and developed by Chemcomex a.s. was chosen as the reference code. It is a subchannel code designed for computation of thermal-hydraulic safety margins for VVER reactors by solving equations of energy and momentum conservation. As was mentioned above, the experimental database from Stewart had to be replaced by Becker's data. Not even the SUBCAL code was able to predict the onset of critical heat flux on Stewart's data.

The Becker's experiments were analyzed with the codes by using several DFFB correlations as it is shown in the Tab. 3. The deviations are minimal and these results led to the first part of the validation of the code TUBE 2.0. The small deviations in the final wall temperatures were probably caused by the different method of obtaining the convergence error. To completely validate the code TUBE 2.0 another experimental or benchmark data should be used.

\subsection{Comparison of CORRElations}

As was mentioned above, the Stewart's data together with the code TUBE 2.0 led to a selection of best performing post critical correlation.

As predicted, the DFFB equations significantly under/overestimated the experimental data. It is demonstrated in the Fig. 2 which shows calculated data on the $\mathrm{x}$ axis and experimental data on the $\mathrm{y}$ axis. The full black line denotes $0 \%$ deviation and green, resp. red belongs to $25 \%$, resp. $50 \%$ deviation. The top
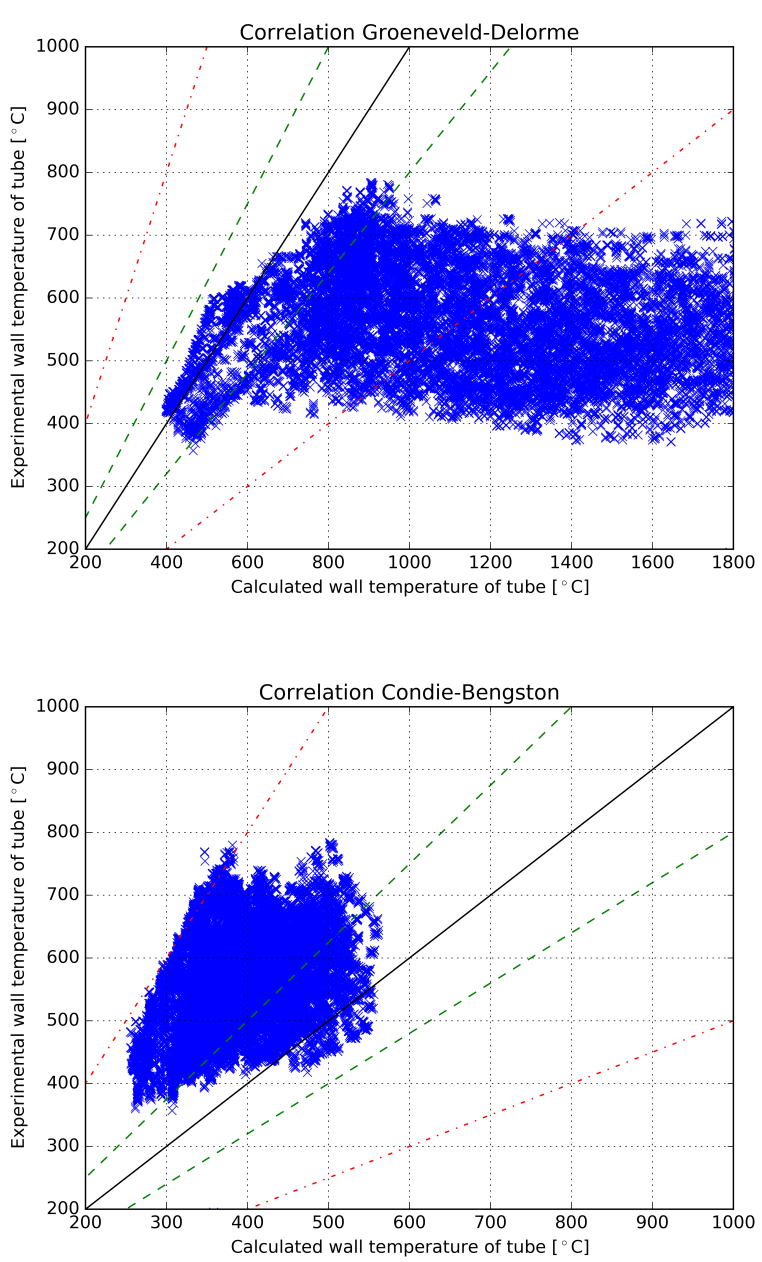

Figure 2. Comparison of experimental and calculated values of wall temperature with use of DFFB correlations.

graph represents correlation from Groeneveld and Delorme which often shows good agreement with DFFB experimental data. However, it significantly overestimates the data. On the other hand, the equation of Condie and Bengston show better agreement with the experimental data, but there is an important underestimation of the data which is inapplicable for safety analyses where the conservative approach is desired.

As presumed, these correlations cannot be used for IAFB regime. Most of them were derived from DittusBoelter relationship considering only convective heat transfer, however, the conductive effect and radiation are neglected.

Correlation Dougall-Rohsenow was similar to Groeneveld-Delorme which also significantly overestimates the data. Further analysis showed that these correlations improve results with higher pressures together with mass fluxes. It is shown in the Fig. 3 where only the data from run with highest pressure (9 $\mathrm{MPa})$ and highest mass flux $\left(2750 \mathrm{~kg} \cdot \mathrm{m}^{-2} \cdot \mathrm{s}^{-1}\right)$ were selected. It is probably caused by the development of flow regime from IAFB to DFFB with modification of inlet parameters. Mosaad [3] suggests to use Weber 


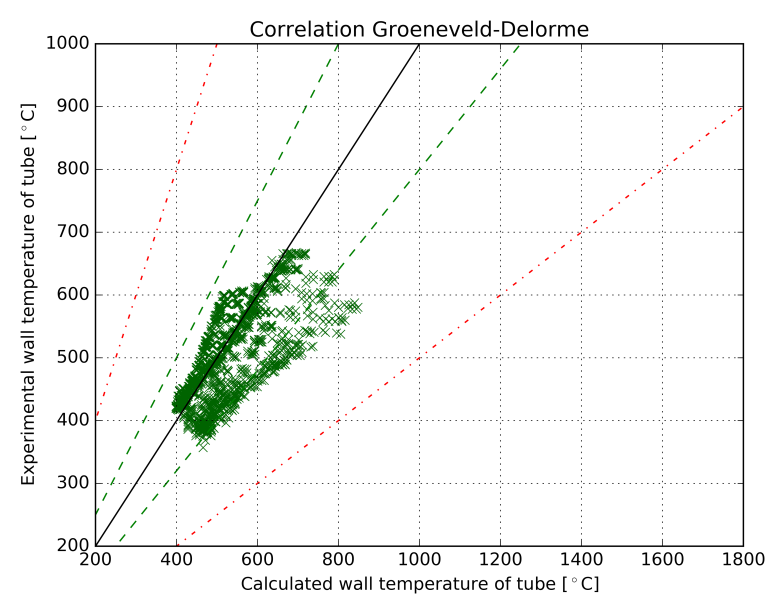

Figure 3. Comparison of experimental and calculated values of wall temperature with selected data from run with highest pressure and mass flux.

number, see eq. (1), for determining the regime in question.

$$
W e=\frac{\rho_{v} \cdot\left(u_{\mathrm{v}}-u_{1}\right)^{2} \cdot\left(d_{\mathrm{h}}-2 \delta\right)}{\sigma}
$$

If the Weber number is below $W e_{\mathrm{cr}}=15$, it is inverted annular film boiling regime and the opposite stands for dispersed flow film boiling. Here is important to note that different literature can provide greater or smaller value of $W e_{c r}$. For the runs with pressure above $8 \mathrm{MPa}$, Weber number always exceeded specified value.

The Groeneveld's tables (see the top part of Fig. 5) gave the best result and were selected as best performing correlation. The points are uniformly arranged across the center line. There were not observed pressure or inlet subcooling effects on heat transfer coefficient, however with reducing the data set for runs with the smallest mass flux the accuracy increased. The tables were created out of more than 30000 values from several experiments. Groeneveld collected both IAFB and DFFB experimental data and extrapolated tables from it. The outcome of this is a set of tables perfectly capable of predicting post critical heat transfer coefficient by linear interpolation among table values. However, due to the small number of considered experiments featuring low mass fluxes, accuracy for such conditions is limited, see Fig. 4

Finally, the IAFB correlations are presented. As stated before, all three examined correlations (Bromley, Berenson, Breen, and Westwater) show significant similarities; this is also the case for calculation results. The best of them was the Berenson's correlation which is shown in the middle part of Fig. 5 .

It has been observed that with removing values from thermocouples placed in the outlet part of the test section, the accuracy increases. It is probably caused by unstable vapor film close to the end of the test section that has arisen by intensifying the turbulence

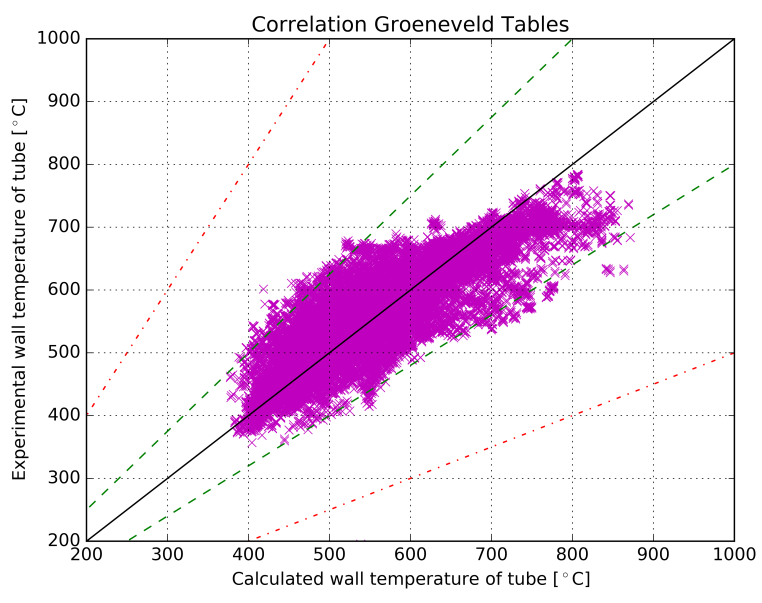

Figure 4. Comparison of experimental and calculated values of wall temperature with reduced data base for the values of smallest mass flux.

effect. Furthermore, outlet section is characterized by highest qualities which could in some cases lead to a change of film boiling regime. It was also observed that with the lowest mass fluxes, the correlation's precision deteriorated.

Mosaad extrapolated his original correlation [18] to greater ranges of pressure and mass flux and claims that the extrapolated correlation has a minimal deviation from Stewart's reduced data. However, these results were not confirmed using the TUBE 2.0 code. Probably there was a mistake in the paper [3] in definitions of the equations or some of them were missing. The data are uniform but the correlation significantly overestimates the data (see the bottom part of Fig. 5). With low mass fluxes and low subcooling the results got slightly better.

All of the mentioned data were statistically processed and the results of average and standard deviations together with the number of points are shown in the Tab. 4 The statistics of reduced data is demonstrated in the Tab. 5 where the improvements, resp. deterioration are highlighted with green, resp. red color.

\section{Conclusions}

The new computation code TUBE 2.0 was presented. One step of the complex validation process (code-tocode comparison) was done using Becker's experimental data and subchannel code SUBCAL. The results of five correlations are shown in Tab. 3 with minimal deviations. The deviations originate probably in different convergence methods that were used. It was shown that for simple geometry - an isolated channel, it is not necessary to use complex codes designed for thermal-hydraulic subchannel analysis of larger geometries. The use of simple and faster codes as TUBE 2.0 is satisfactory. 


\begin{tabular}{l|c|c|c} 
Correlation & AVG [\%] & STD [\%] & N [-] \\
\hline \hline Dougall-Rohsenow & 53.12 & 71.46 & 25897 \\
Groeneveld-Delorme & 146.04 & 147.12 & 22929 \\
Condie-Bengston & -29.32 & 12.07 & 25895 \\
Groeneveld's tab. & 1.33 & 10.56 & 25897 \\
Bromley & 4.06 & 19.72 & 25897 \\
Berenson & 1.56 & 17.95 & 25897 \\
Breen-Westwater & 10.64 & 19.98 & 25897 \\
Mosaad-Johannsen & 75.02 & 25.19 & 15569
\end{tabular}

TABLE 4. Overall statistic analysis of correlations compared with Stewart's experimental data.

\begin{tabular}{l|c|c|c|c} 
Correlation & Reduction & AVG [\%] & STD [\%] & N [-] \\
\hline \hline Berenson & without last TCs & 6.60 & 16.76 & 10904 \\
Dougall-Rohsenow & $\uparrow p=9 \mathrm{MPa}$ & 7.49 & 33.66 & 4161 \\
Dougall-Rohsenow & $\uparrow G=2750 \mathrm{~kg} \cdot \mathrm{m}^{-2} \cdot \mathrm{s}^{-1}$ & 11.69 & 7.66 & 2565 \\
Groeneveld-Delorme & $\uparrow p, \uparrow G, \downarrow h$ & 6.82 & 13.70 & 1368 \\
Groeneveld's tab. & $\downarrow G=120 \mathrm{~kg} \cdot \mathrm{m}^{-2} \cdot \mathrm{s}^{-1}$ & 22.47 & 15.44 & 1501 \\
Groeneveld's tab. & $\uparrow G=2750 \mathrm{~kg} \cdot \mathrm{m}^{-2} \cdot \mathrm{s}^{-1}$ & 2.31 & 7.36 & 2565 \\
Groeneveld's tab. & $G=215-2750 \mathrm{~kg} \cdot \mathrm{m}^{-2} \cdot \mathrm{s}^{-1}$ & 0.0003 & 0.09 & 1368 \\
Mosaad-Johannsen & $\downarrow G=120 \mathrm{~kg} \cdot \mathrm{m}^{-2} \cdot \mathrm{s}^{-1}$ & 40.14 & 19.43 & 1330 \\
Berenson & $\downarrow G=120 \mathrm{~kg} \cdot \mathrm{m}^{-2} \cdot \mathrm{s}^{-1}$ & 25.79 & 13.41 & 1501 \\
Mosaad-Johannsen & $\downarrow h=50 \mathrm{~kJ} \cdot \mathrm{kg}^{-1}$ & 64.70 & 23.60 & 5386 \\
Condie-Bengston & $\uparrow h=255 \mathrm{~kJ} \cdot \mathrm{kg}^{-1}$ & -16.56 & 8.12 & 3230 \\
Berenson & $\uparrow h=255 \mathrm{~kJ} \cdot \mathrm{kg}^{-1}$ & 15.85 & 22.80 & 3230
\end{tabular}

TABle 5. Statistic analysis of correlations compared with Stewart's experimental data with specific reductions. Green colour stands for improvement and red for deterioration.

After code-to-code comparison of TUBE 2.0, the best performing correlation for inverted annular film boiling regime was found. Extensive analysis was done on basis of Stewart's data. An interesting phenomenon was observed. Not even one correlation, see Tab. 2 was able to predict the onset of the boiling crisis. For that reason, the Stewart's experiments were not used for the part of the validation process of TUBE 2.0. It was probably caused by low pressure and mass flux in the presence of low quality. In these conditions correlations almost reached their declared limit of validity. Although the main reason was probably due to the determination of experimental data. The data served for finding minimum film boiling data, so from the beginning of the crisis, the heat flux has been reduced. Most of the correlations for departure from nucleate boiling ratio are controlled by heat flux. For safety analysis (LOCA etc.) it is then important to find correlations that are capable of predicting the boiling crisis. In order to validate the TUBE 2.0 code more experimental or benchmark data should be used.

After manual setting of onset of film boiling, the comparison of several correlations, see Tab. 1, has been presented. It has been found that correlations determined for dispersed annular film boiling regime, such as Dougall-Rohsenow and Groeneveld-Delorme, were strongly overestimating experimental data, see Fig. 2. Correlation of Condie and Bengston was the only one underestimating the data. This is inappropriate for safety analysis where the conservative approach is desired. Although, in conditions with high pressure and mass flux increase in accuracy was observed, see Fig. 3. This was probably caused by the transition to DFFB regime which was confirmed by comparing the Weber number, see eq. (1), as it is recommended by Mosaad 3 .

The equations for inverted annular film boiling regime - Bromley, Berenson, Breen-Westwater gave almost the same results. The distribution was more uniform and the Berenson's correlation featured the lowest deviation, see Fig. 5. These correlations were designed for IAFB regime. However the best results were reached with tables from Groeneveld, see Fig. 5 Only observed weakness for the tables was low mass flux, see Fig. 4. It is due to the lack of performed experiments with low flow. Nevertheless, the tables could be used and are precise both with DFFB and IAFB regime.

The last examined correlation - Mosaad-Johannsen was supposed to be the most accurate, however large deviations from the experimental data were observed. Uniform bias was clearly visible in the predicted data (see the bottom part of Fig. 5 ) and this caused significant overestimation of the experimental data. Mosaad [3] shows that this correlation is perfect for IAFB data and moreover, it was partly derived from Stewart's data. The only source of this correlation was in Mosaad's paper so it should be applied with caution until its validity is verified.

The overall statistic analysis is shown in the Tab. 4 

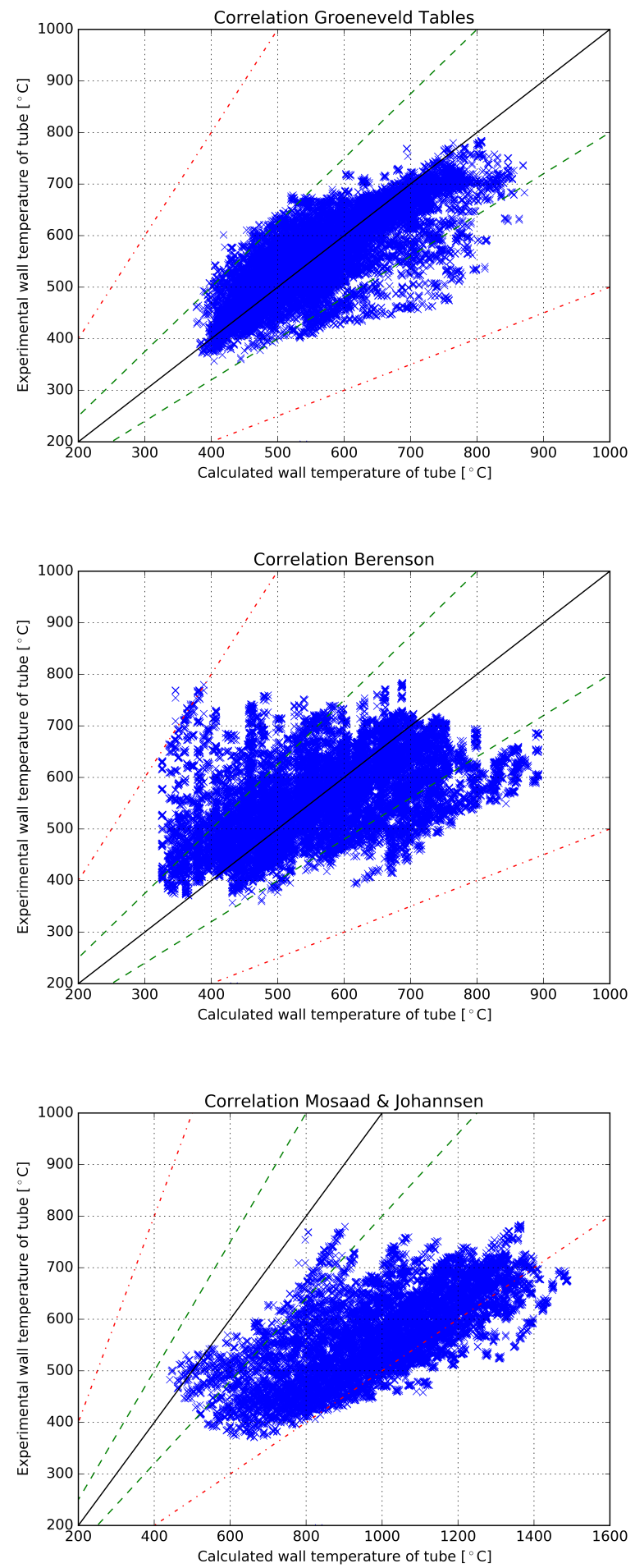

Figure 5. Comparison of experimental and calculated values of wall temperature with use of lookup tables and IAFB correlations. and the analysis with reduced data by pressure, mass flux, resp. subcooling is shown in Tab. 5 More complex analysis of the code TUBE 2.0 and comparison of correlations can be found in the literature [19.

\section{LIST OF SYMBOLS}

AVG Average deviation

CHF Critical heat flux

DFFB Dispersed flow film boiling

IAFB Inverted annular film boiling

STD Standard deviation

TC Thermocouple

$\delta \quad$ Film thickness $[\mathrm{m}]$

$\rho$ Density $\left[\mathrm{kg} \mathrm{m}^{-3}\right]$

$\sigma$ Surface tension $\left[\mathrm{N} \mathrm{m}^{-1}\right]$

$d_{\mathrm{h}}$ Hydraulic diameter [m]

$G$ Mass flux $\left[\mathrm{kg} \mathrm{m}^{-2} \mathrm{~s}^{-1}\right]$

$h$ Inlet subcooling $\left[\mathrm{kJ} \mathrm{kg}^{-1}\right]$

$\mathrm{N}$ Number of points [-]

$p$ Pressure $[\mathrm{Pa}]$

$u$ Velocity $\left[\mathrm{ms}^{-1}\right]$

We Weber's number [-]

cr Index related to the critical value of $W e$

$\mathrm{v}$ Index related to the vapour

l Index related to the liquid

\section{ACKNOWLEDGEMENTS}

The support from Student grant contest from Czech Technical University with code SGS16/252/OHK4/3T/14 is gratefully acknowledged. Many thanks belong to my supervisor Ing. Jiří Čížek and my consultants Ing. Martin Ševeček and Ing. Dušan Kobylka, Ph.D who provided insight and expertise that greatly assisted the research. I would also like to thank Bc. Lubomír Bureš for his constructive criticism and friendly advice during the project work.

\section{REFERENCES}

[1] K. K. Fung. Subcooled and low quality film boiling of water in vertical flow at atmospheric pressure. Ph.D. thesis. University of Ottawa, Ottawa, 1981.

[2] J. C. Stewart. Low Quality Film Boiling at Intermediate and Elevated Pressures. Master thesis. University of Ottawa, Ottawa, Kanada, 1981.

[3] M. Mosaad, K. Johansen. An improved correlation for subcooled and low quality film boiling heat transfer of water at pressures from 0.1 to 8 mpa. Nuclear Engineering and Design vol. 135(issue 3):355-366, 1992. DOI:10.1016/0029-5493(92)90202-7.

[4] M. A. E. Nakla. Experimental and analytical study of inverted annular flow film boiling heat transfer in a vertical tube using r-134a, 2007.

[5] V. CAHA, D. VLCEK. TUBE 2.0-PostCHF Users guide. CTU FNSPE DNR, Prague, 2017.

[6] R. L. Dougall, W. M. Rohsenow. Film boiling on the inside of vertical tubes with upward flow of the fluid at low qualities. Massachusetts Institute of Technology, USA, 1st edn., 1963. 
[7] D. Groenvled, G. Delorme. Prediction of thermal non-equilibrium in the post-dryout regime. Nuclear Engineering and Design 36(1):17-26, 1976. DOI:10.1016/0029-5493(76)90138-2

[8] K. G. Condie, S. J. Bengston, S. L. Richlen. Post-chf heat transfer data - analysis, comparison and correlation, Nepublikováno.

[9] D. Groenveld, L. Leung, A. Vasić, et al. A look-up table for fully developed film-boiling heat transfer. Nuclear Engineering and Design 225(1):83-97, 2003. DOI:10.1016/S0029-5493(03)00149-3

[10] L. A. Bromley. Heat transfer in stable film boiling. U.S. Atomic Energy Commission, Oak Ridge, Tennessee, 6th edn., 1949.

[11] P. J. Berenson. Film-boiling heat transfer from a horizontal surface. Journal of Heat Transfer 83(3):351-356, 1961. DOI:10.1115/1.3682280

[12] Z. Li. Inverted annular film boiling model analysis. Master thesis. The Pennsylvania State University, USA, 2013.

[13] D. Vlcek. Heat Transfer in Pressurized Water Reactors Fuel Rod Bundles at High Void Fraction. Bachelor thesis. CTU FNSPE DNR, Prague, 2016.
[14] N. E. Todreas, M. S. Kazimi. Nuclear systems I. Hemisphere Publ. Comp, New York [etc.], 2nd edn., 1989.

[15] J. Cizek, J. Krejci. SUBCAL-ETE: Dokumentace programu. Chemcomex a.s., Praha 10, 1st edn., 2010.

[16] D. Groenveld, J. Shan, A. Vasić, et al. The 2006 chf look-up table. Nuclear Engineering and Design 237(15-17):1909-1922, 2007. DOI:10.1016/j.nucengdes.2007.02.014.

[17] K. M. Becker, C. H. Ling, S. Hedberg, G. Strand. An experimental investigation of post dryout heat transfer. Royal Institute of Technology, Stockholm, 1st edn., 1983.

[18] M. Mosaad, K. Johanssen. Experimental study of steady-state film boiling heat transfer of subcooled water flowing upwards in a vertical tube. Experimental Thermal and Fluid Science vol. 2(issue 4):477-493, 1989. DOI:10.1016/0894-1777(89)90009-5.

[19] D. Vlcek. Heat Transfer Modelling of PWR Fuel Rods Bundle during a Two-Phase Flow. Research task. CTU FNSPE DNR, Prague, 2016. 